\title{
Isolation and characterization of 3D chitin from a mite species Trachytes pauperior (Parasitiformes: Uropodina)
}

\author{
Emel ÇAKMAK ${ }^{1,2,4}$ (D), Behlül KOÇ BİLİCAN ${ }^{2,3}$ (D)
}

${ }^{1}$ Department of Plant and Animal Production, Güzelyurt Vocational School, Aksaray University, 68100 Aksaray, Turkey

${ }^{2}$ ASUBTAM-Aksaray University, Science and Technology Application and Research Center, 68100 Aksaray, Turkey

${ }^{3}$ Department of Biotechnology, Faculty of Science and Letters, Aksaray University, 68100 Aksaray, Turkey

${ }^{4}$ Corresponding author: emelcakmak@aksaray.edu.tr

ABSTRACT: Chitin is the most abundant structural biopolymer after cellulose in terrestrial ecosystems. Until now, chitin isolation in powder or granule form has been carried out from many macro living groups (Arthropoda, Crustacea, Mollusca etc.). However, studies on chitin characterization of microscopic organisms have remained limited. In this study, three dimensional (3D) chitin extraction was performed for the first time from Trachytes pauperior (Berlese), a mite species. The obtained chitin was observed by light microscopy and characterized by FT-IR, and SEM analysis. Our findings suggest that chitin, which was obtained in high purity and constitutes a large part of the organism's body structure, could be a potential source for future studies.

Keywords: Acari, biopolymer, characterization, extraction, Trachytes pauperior.

Zoobank: http://zoobank.org/97CD8F14-CF8C-457D-ADB5-85613788CE7E

\section{INTRODUCTION}

Chitin is the most abundant biopolymer in nature after cellulose and is found in more than $70 \%$ of the living things in the world. Studies have shown that chitin can be isolated from the outer shells of many living organisms (such as crab, shrimp and lobster), from the cell wall of fungi and some algae and from the whole-body structure of coral, sponges and insects (Rudall, 1963; Wu et al., 2004; Ehrlich et al., 2007; Bo et al., 2012; Arbia et al., 2013; Rahman and Halfar, 2014). The study of Kaya et al. (2014a) showed that bat guano is also new chitin sources. Chitin, whose structure consists of $\beta-1,4$ linked $\mathrm{N}$-acetyl D-glucosamine, has 3 defined allomorphs; alpha, beta and gamma. When previous studies examined, the most common form of chitin was determined as the alpha form and it has been identified in the branches of Arthropoda, Tardigrada, Bryozoa, Mollusca and the cell walls of Fungi (Brimacombe and Webber, 1964; Ehrlich et al., 2007; Al Sagheer et al., 2009). Considering the literature, it has been seen that there is no enough study on the isolation of the three dimensional (3D) chitin. Moreover, the isolated chitins were mostly obtained either powder or granule form of macro-organisms (Fadlaoui et al., 2019; Kardas et al., 2012).

Chitin is known to be non-toxic, biodegradable, edible, biocompatible, antioxidative, antimicrobial, thermally stable, antioncogenic and has a porous surface. These properties enable chitin and its derivatives to be used in numerous economically important applications in a wide variety of fields such as agriculture, medicine, food industry, textiles, and cosmetics (Jeon et al., 2000; Rinaudo, 2006; Krantz and Walter, 2009; Merzendorfer, 2009; Jayakumar et al., 2011; Anitha et al., 2014; Fernando et al., 2016; Hamed et al., 2016; Petrenko et al., 2017). Although chitin has such a wide area of use, the studies are clearly demonstrated that it is generally obtained from macrosized organisms and microscopic creatures are neglected.

One of the most abundant invertebrates living in forest ecosystems are mites and more than 50,000 species have been described (Manu et al., 2018). Especially, Uropodina mites are one of the most widespread and diverse groups of mites living in soil (Kontschán, 2010, 2013; Kontschán et al., 2013). Besides, soil mites are known to play an important ecological role in the forest. For instance, they are reported to participate in soil formation processes and affect productivity (Manu et al., 2018). In the genus Trachytes Michael within the family Trachytidae, up to 30 species have been identified, 23 of which are from Central European countries such as Germany, the Czech Republic, Austria, Poland, Slovakia, Hungary, Ukraine and Romania (Masan, 2003). Trachytes pauperior has a wide ecological tolerance and lives in a variety of habitats (Masan, 2003). This species has been recorded from Europe and Siberia (Masan, 2003), and also reported form Turkey in a PhD dissertation by Bal (2002) and later in MSc dissertation by Özen (2012), but these dissertations have not been published yet. Until now, taxonomic and ecological studies have been conducted on the genus Trachytes in general (Pecina, 1970a,b, 1980; Hutu, 1973, 1982; ZirngieblNicol, 1973; Bloszyk, 1980, 1999; Masan, 2003), but no study has been carried out on the content of chitin. In the current study, chitin isolation was performed for the first time from Trachytes pauperior (Berlese), which was followed out without damaging the 3D structure. 


\section{MATERIALS AND METHODS}

\section{Sample Collection}

The mite specimens identified as Trachytes pauperior were extracted from soil and litter under Quercus sp., Pülümür Valley, TURKEY, 39³5'18.72"N 3951'09.35'E, 1459 m a.s.l., 30 January 2019, using Berlese funnels.

\section{Chitin Extraction}

In total, 100 specimens were washed with distilled water for chitin extraction, any remaining particles were removed and dried at $60{ }^{\circ} \mathrm{C}$ for 3 days for extraction. It was treated at $60{ }^{\circ} \mathrm{C}$ in $2 \mathrm{M} 250 \mathrm{~mL} \mathrm{HCl}$ solution for 6 hours to remove the minerals in the structure. At the end of this period, the samples were washed with pure water until they reached neutral $\mathrm{pH}$ by keeping their shape. Subsequently, samples were treated with $2 \mathrm{M} \mathrm{NaOH}$ solution at $85{ }^{\circ} \mathrm{C}$ for 8 hours to remove protein residues in their structure. At the end of the treatment, the samples were washed again with pure water until they reached neutral $\mathrm{pH}$ and dried for 3 days at $60^{\circ} \mathrm{C}$.

\section{Fourier Transform Infrared Spectroscopy (FT-IR)}

The infrared spectra of the chitin isolates obtained from the species T. pauperior in 3D were recorded using Perkin Elmer Spectrometer in the range $4000-650 \mathrm{~cm}^{-1}$ at $8 \mathrm{~cm}^{-1}$ resolution in the wavelength range of $600-4000 \mathrm{~cm}^{-1}$. Besides, the 64 scans were averaged to improve the signal-to-noise ratio.

Scanning Electron Microscopy (SEM) and Light microscopy image

The surface morphology of the isolates of the 3D chitin was demonstrated with the ZEISS LS-10 Life Science Scanning Electron Microscopy device. To get better images, the material was gold-plated before the analysis via Cressington sputter-coated 108 Auto, TED PELLA, INC. The 3D chitin produced from T. pauperior was also observed by light microscopy in 5X-60X magnification (Leica DM4000 B LED). The chitin was imaged in ambient conditions using glass slide. Besides, the natural T. pauperior structure (without chitin isolation) was examined by light microscopy (Leica Z6 APO).

\section{RESULTS}

\section{FTIR}

FTIR spectrum of chitin isolates obtained from the species T. pauperior in 3D was given in Figure 1 and Table 1. It is clearly observed that the Amide I band is divided into two peaks in the FTIR spectrum of the 3D chitin isolate from $T$. pauperior (Fig. 1 and Table 1), which shows the compatibility of this chitin with $\alpha$-form. The second important band for the chitin is the Amide II band, which is found around $1552 \mathrm{~cm}^{-1}$ for a pure chitin. The recorded Amide II band for the 3D chitin isolate from T. pauperior is 1556 $\mathrm{cm}^{-1}$. Thus, the Amide II band was also compatible with the literature and reveals the purity of the 3D chitin obtained from T. pauperior as an alpha chitin.
SEM and Light microscopy image

SEM images recorded to illuminate the surface morphology of the chitin isolated from T. pauperior in 3D were shown in Figure 2. It was clearly seen in the recorded images that the 3D structure was preserved during the isolation of the chitin and formed a large part of the organism's structure (Figs 2A-C). Looking at the images recorded at different magnifications, it was clearly demonstrated that the structure consists of tubercles with nanofibers and pores, which looks like the pattern of the cuticular cover is the nanoscale images of the chitin inside the cuticle. The same phenomenon can be observed using white light microscopy. The chitin isolated from T. pauperior as described above, possess 3D arrangement (Figs $3 \mathrm{~A}, \mathrm{~B})$. It is worth noting that these specific structures of mite chitin are extremely sensitive to drying at room temperature. Thus, to prevent degradation of 3D morphology, the samples were immediately scanned.

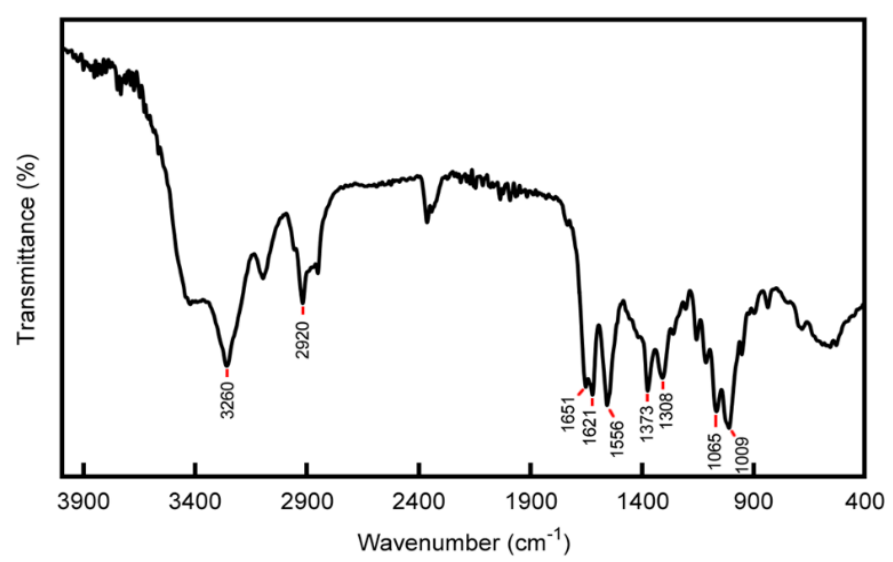

Figure 1. FTIR spectrum of the $3 \mathrm{D}$ chitin isolate from $T$. pauperior.

\section{DISCUSSION}

For the first time, 3D chitin was successfully isolated from the body structure of the species T. pauperior in the current study. As a result, it has been demonstrated that the 3D isolated chitin constitutes a large part of the organism's body structure. The presence of chitin in the peritrophic membrane of Acarus siro (Acari: Acaridae) has only been confirmed so far by Sobotnik et al. (2008). However, the study of Sobotnik et al. (2008) was not conducted on the characterization of chitin, only showing that the presence of chitin in the peritrophic membrane provides an opportunity for the application of chitin effectors as acaricides. As it is known, one of the pathways of chitin synthesis in Acari is found in the hypodermis under the cuticle (Mothes and Seitz, 1981). The mite cuticle consists of a wax-containing epicuticle and a thin procuticle (Mothes and Seitz, 1982, 1984). In other words, the nano-sized imaging of the $3 \mathrm{D}$ chitin was obtained from the procuticle region of the cuticle layer of the integument.

FTIR spectroscopy is one of the powerful tools for structural analysis of poly-saccharides, including the chitin (Żółtowska-Aksamitowska et al., 2018). Vibration spectra are also sensitive to intramolecular and intermolecular 
Table 1. FTIR spectra of the chitin obtained from Trachytes pauperior.

Wavenumber $\left(\mathrm{cm}^{-1}\right)$ frequency

Functional groups and vibration modes

Classification
Chitin from Trachytes pauperior
Commercial $\alpha-$

chitin

(Kaya et al., 2017)

\begin{tabular}{|c|c|c|c|}
\hline $\mathrm{O}-\mathrm{H}$ stretching & - & 3421 & 3433 \\
\hline $\mathrm{N}-\mathrm{H}$ stretching & & 3260 & $3104-3260$ \\
\hline $\begin{array}{l}\text { CH3 sym. stretch and CH2asym. } \\
\text { stretch }\end{array}$ & Aliphatic compounds & 2920 & 2940 \\
\hline CH3 sym. stretch & Aliphatic compound & 2852 & 2875 \\
\hline $\mathrm{C}=0$ secondary amide stretch & Amide I & 1651 & 1652 \\
\hline $\mathrm{C}=0$ secondary amide stretch & Amide I & 1621 & 1620 \\
\hline $\mathrm{N}-\mathrm{H}$ bend, $\mathrm{C}-\mathrm{N}$ stretch & Amide II & 1556 & 1552 \\
\hline $\begin{array}{l}\mathrm{CH} 2 \text { bending and } \mathrm{CH} 3 \text { defor- } \\
\text { mation }\end{array}$ & - & 1417 & 1420 \\
\hline $\mathrm{CH}$ bend, $\mathrm{CH} 3$ sym. deformation & - & 1373 & 1375 \\
\hline $\mathrm{CH} 2$ wagging & $\begin{array}{l}\text { Amide III, components } \\
\text { of protein }\end{array}$ & 1308 & 1307 \\
\hline $\begin{array}{l}\text { Asymmetric bridge oxygen } \\
\text { stretching }\end{array}$ & & 1154 & 1154 \\
\hline $\begin{array}{l}\text { Asymmetric in-phase ring } \\
\text { stretching mode }\end{array}$ & & 1112 & 1112 \\
\hline $\begin{array}{l}\mathrm{C}-\mathrm{O}-\mathrm{C} \text { asym. stretch in phase } \\
\text { ring }\end{array}$ & Saccharide rings & 1065 & 1067 \\
\hline $\mathrm{C}-\mathrm{O}$ asym. stretch in phase ring & - & 1009 & 1008 \\
\hline CH3 wagging & along chain & 951 & 951 \\
\hline $\mathrm{CH}$ ring stretching & Saccharide rings & 896 & 892 \\
\hline
\end{tabular}

interactions as well as to the geomolecular molecule. Recently, this method has been successfully applied to identify three known isomorphs of chitin $(\alpha, \beta$ and $\gamma)$ (Kaya et al., 2017). There are two characteristic peaks for the chitin. The first one is the Amide I band. Looking at the information in the literature, if this peak is an undivided peak around $1640 \mathrm{~cm}^{-1}$, the chitin is called $\beta$-form, however; the two sharp peaks divided around 1660 and 1620 $\mathrm{cm}^{-1}$ are called $\alpha$-form (Jang et al., 2004; Kaya et al., 2017). In the FTIR analysis, it was detected that the isolated chitin both was in $\alpha$-form and included peaks that were quite compatible with the literature. The Amide I band can be sharply shown at 1651 and $1621 \mathrm{~cm}^{-1}$ in the spectrum of the chitin isolate, almost completely consistent with the literature (Table 1).

Generally, the chitin can be grouped in four different ways according to the surface morphology (Kaya et al., 2014b). The first form is a smooth surface morphology without any nanofibers and pores. The second form consists of nanofibers but does not contain pores. The third form has nanofibers and co-pores. The fourth form exhibits two types of pores of different sizes (one large and one small) in combination with nanofibers. In this study, the SEM analysis revealed that the $3 \mathrm{D}$ chitin isolated by consists of nanofibers and nanopores, which consistent with the other Arachnida species (Kaya et al., 2016). Similarly, it has been previously stated in the literature that the surface morphology of $\alpha$-chitin consists of nanofibers and natural pores (Al Sagheer et al., 2009; Ifuku et al., 2011; Kaya et al., 2013; Mushi et al., 2014). In the study of Seyyar and Demir (2020), the chitin from external skeleton of an opilionid species, Phalangium opilio (Arachnida: Opiliones) was firstly extracted, and the chitin has been found to have nanofiber and nanoporous surface and alpha form. Additionally, the chitin characterization of two spider specimens demonstrated similar surface morphology (Kaya et al. 2014b). In 2020, Machałowski and coworkers obtained chitin from spider source retaining its unique shapes, including the 3D tubular architecture. 

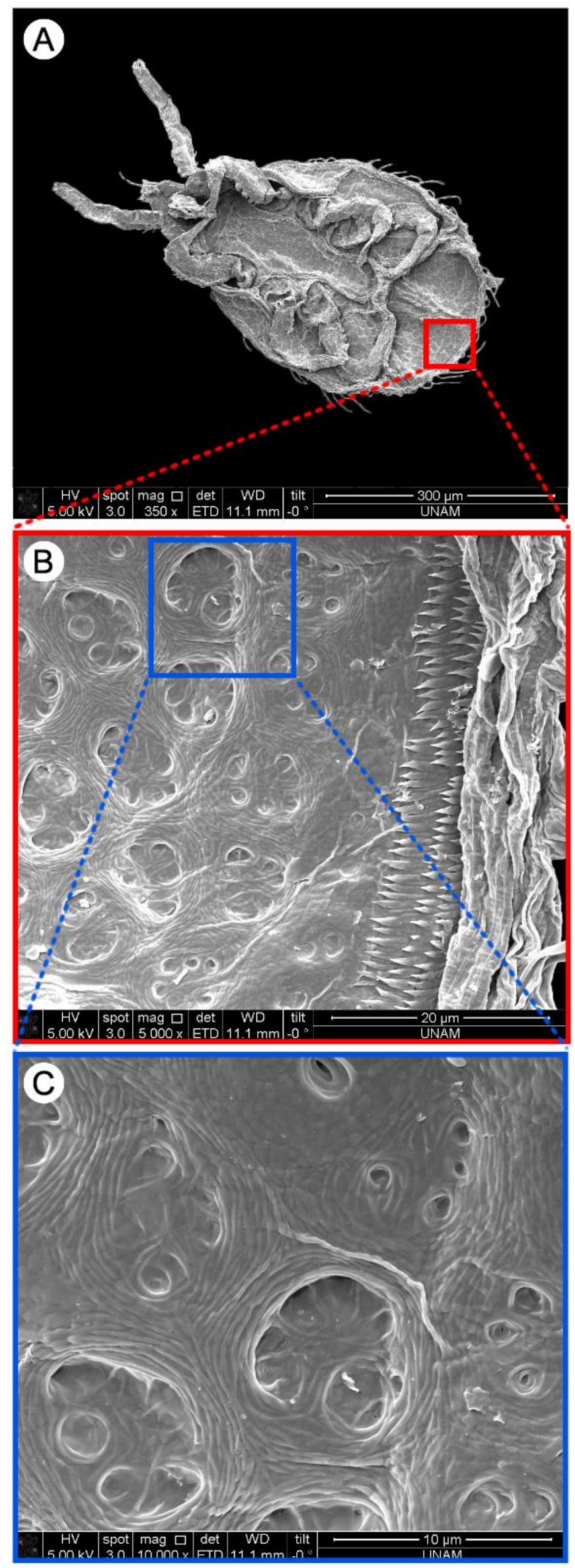

Figure 2. SEM images of chitin isolates from T. pauperior in 3D.
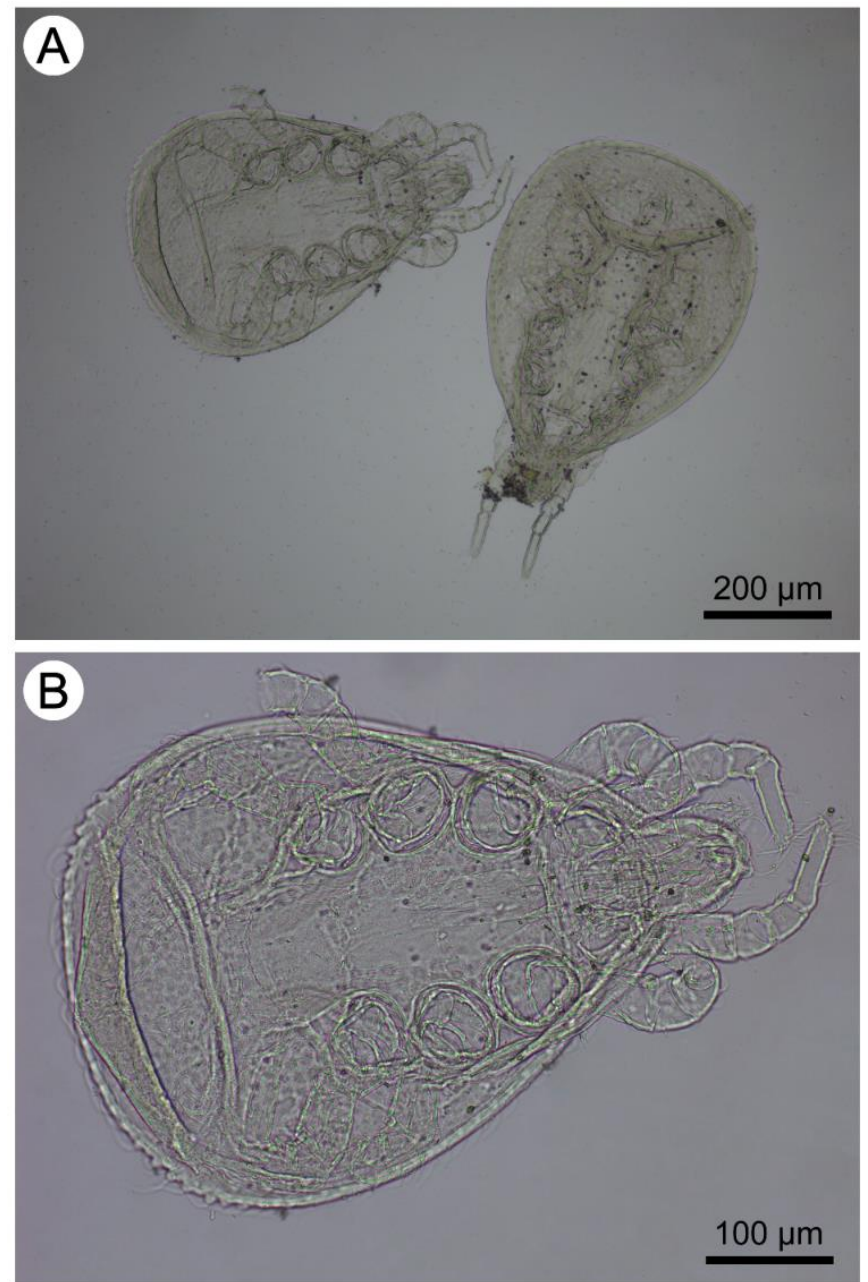

Figure 3. Purified chitin of T. pauperior of light microscopy modus (0-60X).

In addition to SEM images, the light microscopy clearly showed that the 3D structure was preserved without damaging. These part that looks like the pattern of the cuticular cover is the nanoscale images of the chitin inside the cuticle. Although we could not give the ratio of the chitin because it is very small organism, we predict that the content of the chitin is close to the Arthropoda, since we can isolate the 3D structure without deterioration. Thus, the results of the current study demonstrated that as a microscopic organism, T. pauperior, could be an alternative source of chitin for future applications. We suggest that the discovery of chitin within other representatives of the mite species is the next step.

\section{Authors' contributions}

Emel Çakmak: Investigation (equal), formal analysis (equal), methodology (equal), visualization (lead), writing - original draft (supporting), writing - review \& editing (lead). Behlül Koç-Bilican: Investigation (equal), formal analysis (equal), methodology (equal), visualization (supporting), writing - original draft (lead), writing - review \& editing (supporting).

\section{Statement of ethics approval}

Not applicable. 


\section{Funding}

There is no fund for the present study.

\section{Conflict of interest}

The authors declare that there is no conflict of interest regarding the publication of this paper.

\section{Acknowledgement}

We would like to thank Prof. Dr. Salih DOĞAN (Erzincan Binali Yıldırım University, Turkey) for supporting over this manuscript.

\section{REFERENCES}

Al Sagheer, F., Al-Sughayer, M., Muslim, S. and Elsabee, M. 2009. Extraction and characterization of chitin and chitosan from marine sources in Arabian Gulf. Carbohydrate Polymers, 77 (2): 410-419. doi: 10.1016/j.carbpol.2009.01.032

Anitha, A., Sowmya, S., Kumar, P.S., Deepthi, S., Chennazhi, K. et al. 2014. Chitin and chitosan in selected biomedical applications. Progress in Polymer Science, 39 (9): 1644-1667. doi: 10.1016/j.progpolymsci.2014.02.008

Arbia, W., Arbia, L., Adour, L. and Amrane, A. 2013. Chitin extraction from crustacean shells using biological methods-a review. Food Technology and Biotechnology, 51 (1): 12-25.

Bal, D.A. 2002. Uropodid (Acari, Gamasida, Uropodina) fauna of Erzincan and Erzurum provinces. PhD Dissertation. Graduate School of Natural and Applied Sciences, Atatürk University, Erzurum, Turkey, 328 pp. [In Turkish]

Bloszyk, J. 1980. Mites of the genus Trachytes Michael, 1894 (Acari, Mesostigmata) in Poland. Prace Komisji Biologicznej, Poznan, 54: 1-51.

Bloszyk, J. 1999. Geographical and ecological variability of mites of the kohort Uropodina (Acari: Mesostigmata) in Poland. I. Uropodine mites of oak-hornbeam forests (Carpinion betuli). Kontekst, Poznan, Poland, 245 pp. [In Polish]

Bo, M., Bavestrello, G., Kurek, D., Paasch, S., Brunner, E. et al. 2012. Isolation and identification of chitin in the black coral Parantipathes larix (Anthozoa: Cnidaria). International Journal of Biological Macromolecules, 51 (1-2): 129-137.

doi: 10.1016/j.ijbiomac.2012.04.016

Brimacombe, J.S. and Webber, J.M. 1964. Mucopolysaccharides: chemical structure, distribution and isolation. Elsevier, Amsterdam, The Netherlands, 181 pp.

Ehrlich, H., Maldonado, M., Spindler, K., Eckert, C., Hanke, T. et al. 2007. Evidence of chitin as a component of the skeletal fibers of marine sponges. Part I. Verongidae (Demospongia: Porifera). Journal of Experimental Zo-
ology-B: Molecular and Developmental Evolution, 308 (4): 347-356.

doi: 10.1002/jez.b.21156

Fadlaoui, S., El Asri, O., Mohammed, L., Sihame, A., Omari, A. and Melhaoui, M. 2019. Isolation and characterization of chitin from shells of the freshwater crab Potamon algeriense. Progress on Chemistry and Application of Chitin and its Derivatives, 24: 23-35. doi: 10.15259/PCACD.24.002

Fernando, L.A.T., Poblete, M.R.S., Ongkiko, A.G.M. and Diaz, L.J.L. 2016. Chitin extraction and synthesis of chitinbased polymer films from Philippine blue swimming crab (Portunus pelagicus) shells. Procedia Chemistry, 19: 462-468.

doi: 10.1016/j.proche.2016.03.039

Hamed, I., Özogul, F. and Regenstein, J.M. 2016. Industrial applications of crustacean by-products (chitin, chitosan, and chitooligosaccharides): A review. Trends in Food Science \& Technology, 48: 40-50. doi: $10.1016 /$ j.tifs.2015.11.007

Hutu, M. 1973. Gangsystematik der Parasitiformes. Teil 145. Zur Kenntnis der Uropodiden-Fauna Rumäniens. Neue Uropodiden-Arten der Gattungen Trachytes Michael, 1894, Dinychus Kramer, 1886 und Trachyuropo$d a$ (Berlese, 1888) Hirschmann u. Zirngiebl-Nicol, 1961 nov. comb. Acarologie, Schriftenreihe für Vergleichende Milbenkunde, 19: 45-51.

Hutu, M. 1982. Strukturelle Eigenschaften Von Uropodiden-Zoenosen In Der Streuschicht Verschiedener Walottypen Laengs Eines Hoehengradienten. Pedobiologia, 23 (1): 68-89.

Ifuku, S., Nomura, R., Morimoto, M. and Saimoto, H. 2011. Preparation of chitin nanofibers from mushrooms. Materials, 4 (8): 1417-1425. doi: $10.3390 / \operatorname{ma} 4081417$

Jang, M.K., Kong, B.G., Jeong, Y.I., Lee, C.H. and Nah, J.W. 2004. Physicochemical characterization of $\alpha$-chitin, $\beta$ chitin, and $\gamma$-chitin separated from natural resources. Journal of Polymer Science Part A: Polymer Chemistry, 42 (14): 3423-3432. doi: $10.1002 /$ pola.20176

Jayakumar, R., Prabaharan, M., Kumar, P.S., Nair, S. and Tamura, H. 2011. Biomaterials based on chitin and chitosan in wound dressing applications. Biotechnology Advances, 29 (3): 322-337.

doi: 10.1016/j.biotechadv.2011.01.005

Jeon, Y.-J., Shahidi, F. and Kim, S.-K. 2000. Preparation of chitin and chitosan oligomers and their applications in physiological functional foods. Food Reviews International, 16 (2): 159-176. doi: 10.1081/FRI-100100286

Kardas, I., Struszczyk, M.H., Kucharska, M., van den Broek, L.A., van Dam, J.E. and Ciechańska, D. 2012. Chitin and chitosan as functional biopolymers for industrial ap- 
plications. In: The European Polysaccharide Network of Excellence (EPNOE). Navard, P. (Ed.), Springer, Vienna, Austria, 329-373.

doi: 10.1007/978-3-7091-0421-7_11

Kaya, M., Tozak, K. Ö., Baran, T., Sezen, G. and Sargin, I. 2013. Natural porous and nano fiber chitin structure from Gammarus argaeus (Gammaridae Crustacea). Excli Journal, 12: 503-510.

Kaya, M., Seyyar, O., Baran, T. and Turkes, T. 2014a. Bat guano as new and attractive chitin and chitosan source. Frontiers in Zoology, 11 (1): 1-10.

Kaya, M., Seyyar, O., Baran, T., Erdoğan, S. and Kar, M. 2014b. A physicochemical characterization of fully acetylated chitin structure isolated from two spider species: With new surface morphology. International Journal of Biological Macromolecules, 65: 553-558. doi.org/10.1016/j.ijbiomac.2014.02.010

Kaya, M., Baublys, V., Sargin, I., Šatkauskienè, I., Paulauskas, A. et al. How taxonomic relations affect the physicochemical properties of chitin. Food Biophysics, 11 (1): 10-19. doi: 10.1007/s11483-015-9404-5

Kaya, M., Mujtaba, M., Ehrlich, H., Salaberria, A.M., Baran, T. et al. 2017. On Chemistry of $\gamma$-chitin. Carbohydrate Polymers, 176: 177-186. doi: 10.1016/j.carbpol.2017.08.076

Kontschán, J. 2010. Taxonomical and faunistical studies on the Uropodina mites of Greece (Acari: Mesostigmata). Opuscula Zoologica Budapest, 41 (1): 29-38.

Kontschán, J. 2013. Species of the genus Trachytes Michael, 1894 (Acari: Uropodina: Trachytidae) of Romania. Acta Zoologica Academiae Scientiarum Hungaricae, 59 (4): 321-336.

Kontschán, J., Park, S.J., Yoon, T.J. and Choi, W.Y. 2013. Uropodina mites from Korean Peninsula (Acari: Mesostigmata). Ad Librum, Budapest, Hungary, 70 pp.

Krantz, G.W. and Walter, D.E. 2009. A manual of Acarology. Third Edition. Texas Tech University Press, Lubbock, Texas, USA, 807 pp.

Machałowski, T., Amemiya, C. and Jesionowski, T. (2020). Chitin of Araneae origin: Structural features and biomimetic applications: A review. Applied Physics A, 126 (9): 1-17.

doi: $10.1007 / s 00339-020-03867-x$

Manu, M., Bancila, R.I. and Onete, M. 2018. Importance of moss habitats for mesostigmatid mites (Acari: Mesostigmata) in Romania. Turkish Journal of Zoology, 42 (6): 673-683.

doi: $10.3906 /$ zoo-1712-6

Masan, P. 2003. Identification key to Central European species of Trachytes (Acari: Uropodina) with rede- scriptions, ecology and distribution of Slovak species. European Journal of Entomology, 100 (3): 435-448. doi: 10.14411/eje.2003.066

Merzendorfer, H. 2009. Chitin: structure, function, and metabolism. In: The Sugar Code: Fundamentals of Glycosciences. Gabius, H.-J. (Ed.), Wiley, VCH, Weinheim, Germany, 217-229.

Mothes, U. and Seitz, K.A. 1981. A possible pathway of chitin synthesis as revealed by electron microscopy in Tetranychus urticae (Acari, Tetranychidae). Cell and Tissue Research, 214 (2): 443-448.

Mothes, U. and Seitz, K.A. 1982. Action of the microbial metabolite and chitin synthesis inhibitor nikkomycin on the mite Tetranychus urticae; an electron microscope study. Pesticide Science, 13 (4): 426-441.

Mothes, U. and Seitz, K.A. 1984. Fine structure of the cuticle and structural changes occurring during moulting in the mite Tetranychus urticae. I. Fine structure of the cuticle. Acarologia, 25 (3): 253-258.

Mushi, N.E., Butchosa, N., Salajkova, M., Zhou, Q. and Berglund, L.A. 2014. Nanostructured membranes based on native chitin nanofibers prepared by mild process. Carbohydrate Polymers, 112: 255-263. doi: 10.1016/j.carbpol.2014.05.038

Özen, E. 2012. Uropodid (Acari: Mesostigmata: Uropodina) fauna of Kelkit Valley. MSc Dissertation. Graduate School of Natural and Applied Sciences, Erzincan University, Erzincan, Turkey, 128 pp. [In Turkish]

Pecina, P. 1970a. Contribution to the knowledge of Uropodidae (Berlese, 1892) sensu Hirschmann et Zirngiebl-Nicol, 1964, of the environs of Prague (Acari, Mesostigmata). Acta Universitatis Carolinae. Biologica, 1968: 417-434.

Pecina, P. 1970b. Czechoslovak uropodid mites of the genus Trachytes Michael, 1894 (Acari, Mesostigmata). Acta Universitatis Carolinae. Biologica, 1969: 39-59.

Pecina, P. 1980. Additional knowledge of members of the genus Trachytes Michael, 1894 (Acari, Mesostigmata) from Czechoslovakia. Acta Universitatis Carolinae. Biologica, 1978: 389-407.

Petrenko, I., Bazhenov, V.V., Galli, R., Wysokowski, M., Fromont, J. et al. 2017. Chitin of poriferan origin and the bioelectrometallurgy of copper/copper oxide. International Journal of Biological Macromolecules, 104: 1626-1632.

doi: 10.1016/j.ijbiomac.2017.01.084

Rahman, M.A. and Halfar, J. 2014. First evidence of chitin in calcified coralline algae: new insights into the calcification process of Clathromorphum compactum. Scientific Reports, 4: 6162. doi: $10.1038 /$ srep 06162 
Rinaudo, M. 2006. Chitin and chitosan: Properties and applications. Progress in Polymer Science, 31 (7): 603632.

doi: 10.1016/j.progpolymsci.2006.06.001

Rudall, K. 1963. The chitin/protein complexes of insect cuticles. Advances in Insect Physiology, 1: 257-313. doi: 10.1016/S0065-2806(08)60177-0

Seyyar, F. and Demir, H. 2020. Extraction and physicochemical characterization of chitin from Phalangium opilio Linnaeus, 1758 (Arachnida: Opiliones). Acta Biologica Turcica, 33 (4): 258-263.

Sobotnik, J., Kudlikova-Krizkova, I., Vancova, M., Munzbergova, Z. and Hubert, J. 2008. Chitin in the peritrophic membrane of Acarus siro (Acari: Acaridae) as a target for novel acaricides. Journal of Economic Entomology, 101 (3): 1028-1033.

doi: 10.1093/jee/101.3.1028
Wu, T., Zivanovic, S., Draughon, F.A. and Sams, C.E. 2004. Chitin and chitosan value-added products from mushroom waste. Journal of Agricultural and Food Chemistry, 52 (26): 7905-7910. doi: 10.1021/jf0492565

Zirngiebl-Nicol, I. 1973. Gangsystematik der Parasitiformes. Teil 134. Wiederbeschreibung von 7 bekannten Uroseius-Arten (Uropodini, Uropodinae). Acarologie, 19: 5-10.

Żółtowska-Aksamitowska, S., Tsurkan, M.V., Lim, S.C., Meissner, H., Tabachnick, K. et al. 2018. The demosponge Pseudoceratina purpurea as a new source of fibrous chitin. International Journal of Biological Macromolecules, 112: 1021-1028. doi: 10.1016/j.ijbiomac.2018.02.071

Edited by: Salih Doğan

Reviewed by: Two anonymous referees

Citation: Çakmak, E. and Koç Bilican, B. 2021. Isolation and characterization of 3D chitin from a mite species Trachytes pauperior (Parasitiformes: Uropodina). Acarological Studies, 3 (2): 66-72. 